\title{
Research on English Teaching Based on Non-verbal Cross-cultural Communication
}

\author{
Lei $\mathrm{Yu}^{1, a}$, Zhenguo Qi ${ }^{2, b}$ \\ ${ }^{1}$ School of Foreign Language Shenyang Aerospace University, Shenyang 110136, China; \\ ${ }^{2}$ School of Educational Technology Shenyang Normal University, Shenyang 110034, China; \\ ayuleicathy@126.com, bqizhenguo@126.com
}

Keywords: non-verbal cross-cultural communication; English teaching; Linguistic behavior; cultural conflict

\begin{abstract}
The purpose of integrating non-verbal cross-cultural communication into the English teaching is to understand the behaviors and methods of non-verbal communication in the multi-cultural environment so as to resolve the differences and conflicts between the English culture and the mother tongue, overcome the cultural barriers and promote the English teaching overall. In China, non-verbal cross-cultural communication has been ignored for a long time in English teaching, while the aim of English teaching is to accurately use verbal and non-verbal behaviors to carry out the cross-cultural communication. To achieve it, the English teachers should improve their own cross-cultural awareness and realize the importance of cultivating the students' abilities in non-verbal cross-cultural communication. This essay starts from the current teaching situation of linguistic communication and illustrates the importance of laying stress on the behaviors, methods and functions in non-verbal communication and advocates integrating non-verbal cross-cultural communication into the English teaching in order to cultivate the students' overall abilities in non-verbal cross-cultural communication.
\end{abstract}

\section{Introduction}

Rapid development of science and technology, economic globalization and increasingly opening up in China make us communicate with the external world more and more widely and frequently. Whether the cultural exchange, business cooperation or folk correspondence developed or not, we all inevitably encounter some cultural issues: different customs, different standard of behaviors, different languages, different values, different religious beliefs and different taboos, which would become the external communicative barriers for us. When peace and development are the theme of the current society, learning how to get along the foreigners harmoniously and how to understand their culture have become the key to the smooth exchanges and co-operations [1]. In this era, we have more opportunities to communicating with foreigners. If we do not have sufficient cross-cultural knowledge and flexible cross-cultural communicative skills, it is difficult to start the interpersonal communication and also difficult to engage in the international economic and trade exchanges. Therefore, it is significant to cultivate the cross-cultural awareness.

\section{The significance of cultivating the cross-cultural awareness}

The cultivation of cross-cultural awareness is the demand of social development in the 21st century. The economic globalization and information integration gradually make the economy in our country become one important part in the economic world. With the expansion of all kinds of communication in depth and breadth, the foreign language education in China has faced new challenges and all kinds of talents who are not only able to use the foreign language fluently, but also know about the foreign cultures are needed in the 21st century, which put forward new requirements and goals for us. The education for foreign language is not only to cultivate the students' ability of applying language, but also to train students to use appropriate linguistic ability in the cross-cultural communication [2]. 
The cultivation of cross-cultural awareness is the need of reforming the foreign language teaching in our country. In the traditional way of teaching, the students can obtain the certain ability in language and can deal with various tests, but they can't use the language flexibly and effectively. As is known to all, the language is closely related to the society and the culture, and fully reflected in the teaching outline, teaching material, classroom teaching, language testing and the second foreign language classroom. In view of this, the revised teaching outlines in junior high school, senior high school and college English have put forward different requirements of understanding all the cultural differences, improving the ability of applying language, especially cross-cultural communication. In other words, learning a foreign language includes not only the linguistic knowledge, but also the culture behind it. The both are necessary.

\section{Concepts}

"Non-verbal communication" refers to those factors containing the valuable information for the receivers or the givers other than the factor of language in a certain communicative environment. These factors can be formed artificially, and also can be formed by the environment [3]. "Cross-cultural communication" refers to the communication between the native speakers and the non-native speakers, and it also refers to any communication between people in the differences of language and culture background. Previously, it is mainly the concern and issue of the cultural anthropology and the ethnology [3]. In recent years, with the rapid pace of reform and opening up, the increasingly frequent foreign interactions, the more and more widely communication between countries, especially the improved social informationization and the changing of time and requirements, more and more language teachers have expressed a keen interest in the "cross-cultural communication”.

\section{The teaching situation in the non-verbal cross-cultural communication}

The study of these barriers to the problems in the non-verbal cross-cultural communication indeed has great practical significance for the English teaching. This is because English teaching is not only to impart the knowledge in language, but more importantly, to cultivate the students' English ability of cross-cultural communication. Only learning the English pronunciation, the rules of grammar and grasping a certain amount of vocabularies does not mean that people have learned it well and can communicate favorably [4]. In the cross-cultural communication, if both parties can't enter the same cultural context, it's easy to create the misunderstanding, and thus make the communication fail. Effective communication in English is that, people must understand the non-verbal expressions such as the speakers' gestures and movements when the English is spoken at the same time. And some authorities say the both (speaking and gestures) are dependable, and in most cases this is right. But in some cases, the speaker's gestures are not consistent with what he said, and the oral expressions are not the same as the meaning of gestures, then people have to use other information to guess the speaker's meaning from the entire situation. In a sense, all the language should be understood in a certain situation, and ignoring the whole context will lead to misunderstanding [5]. So it is more appropriate that English teaching can be seen as one part of the cross-cultural education. Because of the further development of reform and opening up in China, the society has put forward the higher requirement of applying ability in English for university graduates. According to a survey conducted in Zhejiang University in 2003, the requirements for the graduates in the listening, speaking and writing ability are made by $67.25 \%, 71.11 \%$ and $61.48 \%$ respectively in the society. However from these aspects, our education is obviously lagged behind. On the one hand, the exam-oriented education has generally brought quite negative influence, and on the other hand, the traditional education in English has deeply restricted the teachers' roles. The Chinese students, whose English learning have spanned from primary school until university, even into their doctoral stage, totally have studied English for more than ten years and spent most of their time and energy in looking up the dictionaries, remembering the new words and analyzing the structure of sentences. For the Chinese students, with the knowledge of 
vocabularies and grammar, they are able to read and can deal with the exam, but a lot of problems can often be arisen in the cross-cultural communication.

\section{The cultural misunderstanding and the causes of cultural conflicts}

Because the cross-cultural communication in English teaching has long been neglected in China, the cultural misunderstanding and the conflicts occur frequently in cross-cultural communication. In the communication, people often only pay attention to the linguistic communication and think that words are the only means of transferring and identifying the information. They often ignore the non-verbal behavior of the information, or notice their bearing behavior but ignore the information provided by the object and the environment. And some individuals blindly imitate the bearing behaviors of "foreigners" and then make foolish mistakes [2]. These cases have reflected some problems in English teaching.

Question 1: Studying the grammar and vocabulary is the whole part of English learning. With such kind of education, the students have the poor ability of not only sending out information, but also receiving information. So their ability of comprehensive communication is disappointing.

Question 2: The learning method is outdated. English learning is influenced by learning the traditional Chinese characters. The students pay more attention to the understanding of words and sentences, but less attention to chapters; they often focus on the information of receiving, but ignore the information of sending out.

Question 3: The ability of comprehensive language is good, but the understanding of cross-cultural communication is poor and the social skills are lacking. After the linguistic ability has improved to a certain high level, the cultural barriers can show prominently. The linguistic mistakes can be very easy to obtain each other's understanding, but pragmatic failures or cultural misunderstandings can often lead to conflicts, even cause the communicative failure.

\section{Cultivate the students' cross-cultural communicative ability}

In teaching English, the teachers often hope the students can use English accurately, fluently and naturally, just like English natives. But our real goal in English teaching is to teach students to use the linguistic behaviors and non-verbal behaviors appropriately and carry on the cross-cultural communication, rather than change them into Englishmen or Englishwomen [6]. To achieve this goal, English teachers need to improve their own awareness of cross-cultural communication and understand the importance of cultivating the students' non-verbal communicative ability. So the non-verbal cross-cultural communication and the English teaching should be combined in order to cultivate the students' comprehensive ability in cross-cultural communication. Through the English teaching, the teachers can help the students learn the non-verbal communicative behavior and its meanings and features as much as possible. Try to understand the non-verbal communicative behavior and the conflicts between the English culture and the culture of their own motherland, and learn some correct, appropriate methods of ruling out the cultural interference. In English teaching the contents of the non-verbal cross-cultural communication are deserved to explore for the English teachers. The author thinks that the following aspects should be paid attention to:

Help the students correctly understand the meanings and the cultural features of the non-verbal communicative behavior in the structure of words when combining the linguistic behavior with the non-verbal behavior. Here is an example: a poor mother lived too hard to support her children, and she only had a little bit of money in the bank to prepare for something urgent. Now she was in great trouble, she still dare not take out the money. The following is the mother and her children' talking about it. Mama pursed her lips "We do not." She reminded us gently, "want to have to go to bank." We all shook our heads. Here, "shook our heads" must be translated into "nodded." This is because the thinking methods in Chinese and English culture are different. English culture attaches importance to the facts, so in the negative words, people use the negative posture to express confirmation, while their affirmative action means denial. But Chinese culture lays stress on the acknowledgment of attitude to the exchanging object, so in the case, the children nodded to express 
they supported their mother. If they shook their head, it means they were disagreeing. And also Chinese people see other people wearing good clothes and often love to touch it, or even ask where to buy and how much, which is a taboo in English speaking countries.

Introduce and lecture the performances, meanings and functions of non-verbal communicative behavior in English culture and the differences and the conflicts of non-verbal communicative behavior against its native culture, and help the students learn to deal with the cultural differences and conflicts correctly and appropriately. For example, shrug is the posture commonly seen in English culture and many other western countries. The performance of the posture is to wrinkle the forehead, lift the eyebrow, shrug the shoulder, bend the double cubits slightly and open up the palm of both hands, which means "I don't know”, "what way?", "I can’t”, etc. There is no this kind of posture in China. The habit of a Chinese is to shake his head or hand to show the above meanings. But now some Chinese like to learn this western posture. Because they don't know its meaning and often make the nondescript jokes. Another example is about the cultural differences happened at the theatre. When feeling drab, some Chinese audience would whisper, some would go in and out and some would buy something to eat or drink. While the people in English culture can control themselves well at the theater. When feeling boring, they often droop their head or snooze as well, but always keep the upright posture, sitting there wordlessly. They are like entering the church when going into the theatre. The people in English culture feel relaxed and casual in the classroom, but the Chinese people are very serious in class. When filling in the forms and votes, the Chinese generally use a tick and a circle to show the agreement or approval, and a cross is to show denial or disagreement; the people in English culture often use a cross to show agreement and approval. So English learners must know about these aspects and imitate carefully.

Introduce and explain the words and phrases used to represent the non-verbal communicative behavior. For example, the American people wear the "owl" badge to show their worship for wisdom, but the Chinese feel it difficult to understand because the "owl" is not a good omen in China. Conversely, "dragon" is a good omen and the symbol in the Chinese culture; in the western cultures, "dragon" is a monster spraying smoke and spitting fire and is regarded as the incarnation of devil in the Bible. Another example, a Swiss couple, who don't understand Chinese, had meals in a Chinese restaurant in Hong Kong. After ordering their food, they gestured to let the waiter give their dog something to eat. The waiter thought for a while and understood, and then took the puppy into the kitchen. When he returned, he brought a plate of dog meat in soy sauce.

\section{Conclusion}

The cultural conflicts caused by the differences of non-verbal behavior are more important than those of the linguistic behavior. The more fluent speaking the language is, the more serious the cultural conflict which is caused by sending out the wrong and inappropriate non-verbal information becomes, because the non-verbal behavior is generally the revealing of emotion or mood [6]. So the non-verbal communication is the integral part of the communication. Only paying attention to the linguistic communication, rather than the non-verbal communication is only an incomplete communication. Because non-verbal communication is acquired instead of being inborn, it should be an integral part of English teaching. English teaching is not complete and successful without it. The International education has been advocated "To know, to do and to be". The English teaching in China should be closely directed towards the development of education in the world so as to make continuous efforts to cultivate the talents with the quality of cross-cultural communication.

\section{Acknowledgments}

I would like to express my deep appreciation and gratitude to those special people who have supported and assisted me in completing my paper. These special people allowed me to share my vision with them and obtained its fruition through their suggestions, guidance, participation, and encouragement. 


\section{References}

[1]. Song Jihong, English Teaching and Education in Cross-cultural Awareness, The Border Economy and Culture, Vol.58 134-137 October. 2008(In Chinese)

[2]. Yang Pingze, The Cultural Problems of English Teaching in Non-native English Countries, Foreign Language Teaching, Vol.46, pp.72-74, March. 2008(In Chinese)

[3]. Chen Zufu, To Meet the Challenge of Times, and Update the Educational Ideas and Concepts, Teaching and Teaching Material, April.2001 (In Chinese)

[4]. Bi Jiwan, Cultural Barriers and Foreign Language Teaching in Cross-cultural Communication, Longyan Journal, March. 2009(In Chinese)

[5]. Birdwhistell, Ray, Kinesics and Context. Philadelphia. University of Pennsylvania Press. 2006

[6]. Fan Weiwei, Education and Cultivation of Ability in Cross-cultural Communication, Educational Research, August. 2003(In Chinese) 